\section{Research Square}

Preprints are preliminary reports that have not undergone peer review.

They should not be considered conclusive, used to inform clinical practice, or referenced by the media as validated information.

\title{
Analytical Performance of the Point-of-care BIOSYNEX COVID-19 Ag BSS for the Detection of SARS-CoV-2 Nucleocapsid Protein in Nasopharyngeal Swabs: A Prospective Field Evaluation During the COVID-19 Third Wave in France
}

Frédéric Fitoussi

Centre Cardiologique du Nord

Serge Tonen-Wolyec

Université de Kisangani: Universite de Kisangani

Natalio Awaida

Laboratoire de Paris XV

Raphaël Dupont

Centre Cardiologique du Nord

Laurent Belec ( $\square$ laurent.belec@aphp.fr)

Université Paris-Sorbonne: Sorbonne Universite https://orcid.org/0000-0002-5001-0405

Research

Keywords: COVID-19, Rapid diagnostic test, Antigen, Protein N, France.

Posted Date: September 16th, 2021

DOI: https://doi.org/10.21203/rs.3.rs-876550/v1

License: (c) (1) This work is licensed under a Creative Commons Attribution 4.0 International License. Read Full License 


\section{Abstract}

Background: The accuracy and reliability of rapid diagnostic tests are critical for monitoring and diagnosing SARS-CoV-2 infection in the general population. This study aimed to evaluate the analytical performance of the BIOSYNEX COVID-19 Ag BSS (Biosynex Swiss SA, Fribourg, Switzerland) antigen rapid diagnostic test (Ag-RDT), which targets the SARS-CoV-2 N-nucleocapsid protein for the diagnosis of COVID-19. The Ag-RDT was compared with a real-time RTPCR (rtRT-PCR) gold standard for performance measurement.

Methods: Two nasopharyngeal flocked swabs were prospectively collected simultaneously in March and April 2021 from 967 individuals aged $\geq 18$ years tested for SARS-CoV-2 in two private laboratories, Paris, France.

Results: Overall, the Ag-RDT demonstrated high sensitivity, specificity, positive predictive value (PPV), and negative predictive value (NPV) of $81.8 \%$, 99.6\%, $96.6 \%$, and $97.5 \%$, respectively, as well as high or near-perfect agreement (97.0\%), reliability was assessed using Cohen's K-coefficient (0.87), and accuracy was evaluated using Youden index $(\mathrm{J})(81.6 \%)$ in detecting SARS-CoV-2. The analytical performance of the Ag-RDT remained high when there was significant viral shedding (i.e., $\mathrm{N}$ gene $\mathrm{C}_{t}$ values $\leq 33$ on reference RT-PCR). The sensitivity was only $55.2 \%$ in case of low or very low viral excretion ( $C_{t}>33$ ).

Conclusions: The BIOSYNEX COVID-19 Ag BSS Ag-RDT is a promising, potentially simple diagnostic tool, especially in symptomatic COVID -19 or proven infectiousness.

\section{Introduction}

The 2019 coronavirus pandemic (COVID-19) continues to spread worldwide. The effective isolation and early treatment of patients infected by the severe acute respiratory syndrome coronavirus 2 (SARS-CoV-2) require rapid, accurate, and straightforward diagnostic tools.

While currently recommended nucleic acid amplification tests (NAAT), such as real-time reverse transcription-polymerase chain reaction (rtRT-PCR) assays, remain the standard gold cornerstone for the diagnosis of SARS-CoV-2 infection [1,2], viral antigens can be detected using immunological methods [2-4]. Indeed, conducting rtRT-PCR is expensive, time-consuming, and requires special equipment and qualified operators. Point-of-care antigen-detecting rapid diagnostic tests (Ag-RDT) constitute simple and inexpensive alternative tests [3]. Ag-RDT relies on direct detection of SARS-CoV-2 viral proteins in nasal swabs and other respiratory secretions. The $\mathrm{N}$-nucleocapsid protein is frequently targeted because of its relative abundance and conserved structure, or other viral proteins such as the spike protein [4]. Most Ag-RDTs rely on sandwich catching using anti-SARS-CoV-2 monoclonal antibodies to detect viral antigens in the simple-to-use lateral flow immunoassay format allowing results in $<30$ minutes. However, significant variability has been reported about their diagnostic performance and a lack of external validation for many available tests, which still require clinical validation [5-9].

Our study aimed to evaluate the qualitative membrane-based immunochromatographic BIOSYNEX COVID-19 Ag BSS Ag-RDT (Biosynex Swiss SA, Freiburg, Switzerland; reference SW40006) using monoclonal antibodies detecting SARS-CoV-2 N-nucleocapsid protein to diagnose COVID-19 from prospectively collected nasopharyngeal secretion samples in adults living in the Paris region throughout the third wave of the COVID-19 epidemic in France.

\section{Material And Methods}

Rapid antigen test. The BIOSYNEX COVID-19 Ag BSS Ag-RDT consists of a reaction membrane and three buffers (sample, reagent, and absorbent). The reagent buffer contains colloidal gold particles conjugated with monoclonal antibodies directed against the N protein of SARS-CoV-2. Secondary antibodies against the $\mathrm{N}$ protein are catched on the reaction membrane. The manufacturer's instructions were followed to conduct the test by mixing nasopharyngeal secretions with $300 \mu \mathrm{l}$ of dilution buffer in a tube. After one minute, four drops were added to the well on the cassette.

If SARS-CoV-2 antigens are present in the sample, the complexes between the anti-SARS-CoV-2 conjugate and the virus are captured by anti-SARS-CoV-2 monoclonal antibodies specific to the test line area $(T)$. The lack of the $T$ line indicates that the result is negative. A red line appears in the control line area (C) to serve as a procedural control, indicating that the correct sample volume has been added and the membrane has played its role. Reading is carried out after 15 minutes.

Study population and procedures. During the third wave of the COVID-19 epidemic (March and April 2021), two sites had been used to consecutively collect paired nasopharyngeal swabs. Site A was the Centre Cardiologique du Nord, Saint-Denis, France. Site B was the Laboratoire Paris XV, Paris, France. Participants aged $\geq 18$ years and those consenting to undergo two nasopharyngeal swabs for rtRT-PCR and Ag-RDT were included. All participants were given a questionnaire that recorded demographic information (sex and age), reasons for testing, and current and past 14-day symptoms in symptomatic patients. Suggestive symptoms of COVID-19 were headache, fatigue, fever, or upper or lower respiratory symptoms. Asymptomatic individuals were defined as those not reporting any of these symptoms. At both sites, a health care professional first collected nasopharyngeal secretions in one nostril, using the swab provided in the BIOSYNEX COVID-19 Ag BSS kit. This was followed immediately by a nasopharyngeal swab for rtRT-PCR. The COVID-19 antigen rapid test was performed immediately on-site using the Ag-RDT following the manufacturer's instructions. The other nasopharyngeal swabs were stored in physiological serum $(\mathrm{NaCl} 0.9 \%)(1000 \mu \mathrm{L})$ at $+4^{\circ} \mathrm{C}$ and analyzed within $24-48$ hours by the reference rtRT-PCR.

Molecular detection of SARS-CoV-2. The multiplex real-time PCR Novel Coronavirus (2019-nCoV) Real-Time Multiplex RT-PCR Kit (Detection for 3 Genes) (Liferiver \& Shanghai ZJ Bio-Tech Co., Ltd, Shanghai, China) was the reference multiplex molecular detection of SARS-CoV-2 RNA. Individual cycle threshold $\left(C_{t}\right)$ values for each target gene $\left(E, N\right.$ and RdRP). According to manufacturer's recommendations, samples with $C_{t}$ values $\leq 41$ for three or two gene targets were considered as positive; those with $C_{t}$ values $\leq 41$ for only one gene target were possibly positive; samples with $C_{t}$ value $>41$ for the 3 gene targets were negative. 
The $\mathrm{C}_{\mathrm{t}}$ values of the $\mathrm{N}$ gene in the RT-PCR reference were chosen for stratification of viral load in clinical samples because the Ag-RDT detects the SARS-CoV-2 $\mathrm{N}$-nucleocapsid protein.

Statistical analyses. Collected data were analyzed using IBM® SPSS ${ }^{\circledR}$ Statistics 20 software (IBM, SPSS Inc, Armonk, New York, USA). Results of quantitative variables were expressed as medians, however, the proportion with their $95 \%$ confidence interval $(\mathrm{Cl})$ assessed according to the Wilson score bounds were estimated for categorical variables [10]. Comparisons were carried out using Pearson's Chi-square test or Fisher's exact test based on validity conditions. The PPV and NPV were calculated according to Bayes' formulas, taking into account the officially reported prevalence of SARS-CoV-2 RNA positivity in symptomatic patients in the Paris region on 12th April 2021, e.g., around the peak of the third wave epidemic in France (Santé publique France 2021; https://www.santepubliquefrance.fr/ ).

Ethics statement. The purpose of the study was to clinically evaluate the continuous quality improvement program and performance evaluation of COVID-19 management measures following the National Medical-Biological Laboratory Accreditation [11]. The data set was wholly anonymous and contained no identifiable personal health information.

\section{Results}

Paired swab samples were obtained from 967 participants, including 741 from site A and 226 from site B (Table 1). Participants ranged in age from 18 to 95 (median $=34$ years). The main reasons for testing were air travel $(35.6 \%)$, contact-case exposure of an individual infected with SARS-CoV-2 (35.1\%), suspected COVID-19 $(n=212,21.9 \%)$, preoperative assessment (4.4\%), and control of SARS-CoV-2 infection in the previous 30 days (3.0\%). The majority (722, $74.7 \%)$ of included persons were asymptomatic, while a minority (245,25.3\%) reported at least one COVID-19-related symptom [including 212 suspected COVID-19 cases, $29(8.5 \%)$ contact cases, $3(0.9 \%)$ travelers, and 1 (3.0\%) patient with a recent history of COVID-19]. The median symptom duration before sampling was four days (range, $0-20$ days). All comparisons between positive and negative Ag-RDT and rtRT-PCR testing results for both sites and all other variables did not achieve statistical significance (not shown).

Among the 148 positive samples using the gold standard rtRT-PCR, 146 were positive for the three gene targets, and two were positive for only E and N genes. The mean $\pm S D$ of the $C_{t}$ values were $26.1 \pm 4.4$ arbitrary units (a.u.) for the $E$ gene, $26.5 \pm 5.0$ a.u. for the RdRP gene, and $26.9 \pm 5.1$ a.u. for the $N$ gene.

The vast majority $(114 / 123,92.7 \%)$ of positive results appeared within the first five minutes and frequently $(31 / 123,25.2 \%)$ within one minute. Table 2 shows the test results and primary performance characteristics of the BIOSYNEX COVID-19 Ag BSS Ag-RDT compared with the reference rtRT-PCR in the study population according to COVID-19-compatible symptoms. Using rtRT-PCR as the standard, three false-positive BIOSYNEX COVID-19 Ag BSS test results occurred among specimens from asymptomatic $(n=2)$ or symptomatic $(n=1)$ participants. Of the 148 rtRT-PCR positive results, $27(18.2 \%)$ were falsenegative BIOSYNEX COVID-19 Ag BSS (23 specimens from asymptomatic persons and four specimens from asymptomatic persons). Overall, the BIOSYNEX COVID-19 Ag BSS Ag-RDT showed high sensitivity (81.8\%), specificity (99.6\%), PPV (96.6\%), and NPV (97.5\%). Among symptomatic persons, sensitivity was $95.0 \%$, specificity was $99.4 \%$, PPV was $95.6 \%$, and NPV was $96.3 \%$ (Table 2). Within seven days from symptom beginning, the BIOSYNEX COVID-19 Ag BSS AgRDT showed a sensitivity of $96.6 \%$, a specificity of $99.4 \%$, whereas the PPV and NPV were $95.7 \%$ and $99.4 \%$, respectively.

The Table 3 shows the analytical results based on the level of viral excretion assessed by the $\mathrm{N}$ gene $\mathrm{C}_{\mathrm{t}}$ values using the reference rtRT-PCR. Overall, the BIOSYNEX COVID-19 Ag BSS Ag-RDT showed high or almost perfect agreement (97.0\%), reliability using Cohen's K coefficient (0.87), and accuracy using Youden's J index (81.6\%) to detect SARS-CoV-2.

In case of high or very high viral loads $\left(\mathrm{C}_{t} \leq 33\right)$, the BIOSYNEX COVID-19 Ag BSS Ag-RDT had excellent analytical performance, (sensitivities between $83.3 \%$ and $100.0 \%$, specificities of $99.8 \%$, PPV between $98.3 \%$ and $98.6 \%$, and NPV between $97.7 \%$ and $100.0 \%$ ). In case of low or very low viral loads ( $C_{t}>33$ ), the sensitivity of the BIOSYNEX COVID-19 Ag BSS Ag-RDT had reduced analytical performance (sensitivity of only $55.2 \%$ ). In comparison, its specificity remained high (98.8\%). Similar observations were made when the $C_{t}$ values of the $E$ or ORF1ab gene targets were chosen for stratification of viral load in clinical samples (not shown).

Finally, the sensitivity of the BIOSYNEX COVID-19 Ag BSS Ag-RDT varied among the five participant groups as follows: i) travel: $50.0 \%$ (7/14), ii) contact-case exposure: 81.0\% (47/58), iii) preoperative assessment: 50.0\% (2/4); iv) suspected COVID - 19: 96.8\% (61/63), and v) control of SARS-CoV-2 positive test results in the last 30 days: $88.9 \%(8 / 9)$.

\section{Discussion}

We evaluated the analytical performance of the novel point-of-care BIOSYNEX COVID-19 Ag BSS Ag-RDT compared to multiplex rtRT-PCR for detecting SARSCoV-2 RNA as the gold standard in a real-life setting. In this study, the sensitivity of the BIOSYNEX COVID-19 Ag BSS Ag-RDT was lower among specimens from asymptomatic persons (79.4\%) than among specimens from symptomatic persons (95.0\%). It was exceptionally high in patients with suspected COVID19 (96.8\%). Specificity (> 99.0\%) was high in specimens from both asymptomatic and symptomatic groups. The prevalence of SARS-CoV-2 RNA-positive rt-RTPCR results in this population was relatively high (15.3\% overall, $9.4 \%$ for asymptomatic participants, and $32.6 \%$ for symptomatic participants). The estimated PPVs and NPVs of the BIOSYNEX COVID-19 Ag BSS Ag-RDT were elevated in all groups of participants. However, administering the Ag-RDT in lower prevalence settings will likely result in lower predictive values. In the event of significant viral excretion (i.e., $\mathrm{N} \mathrm{gene} \mathrm{C}_{t}$ values below 33 based on reference rtRT-PCR), the BIOSYNEX COVID-19 Ag BSS Ag-RDT showed high sensitivity (from 83.3-100.0\%) and specificity (>99.0\%) for SARS-CoV-2 RNA detection. Concordance, reliability, as well as accuracy were great with the reference assay and PPVs and NPVs above $97.0 \%$. However, the sensitivity of the study Ag-RDT dropped to $55.2 \%$ with low or very low viral shedding $\left(C_{t}>33\right)$. Together, these observations demonstrated the high analytical performance of the BIOSYNEX COVID-19 Ag

Page 3/10 
BSS Ag-RDT. This performance made it suitable for use as point-of-care Ag-RDT in various hospital and non-hospital settings where a rapid diagnosis of SARS-CoV-2 is necessary. Although less sensitive than RT-PCR, the BIOSYNEX COVID-19 Ag BSSAg-RDT could be beneficial due to its quick results, ease of use, and independence from existing laboratory structures. Testing criteria focusing on patients during the early onset of symptoms could further increase its diagnostic value.

The sensitivity of the BIOSYNEX COVID-19 Ag BSS Ag-RDT was $81.8 \%$ overall, and the positive detection rate was comparable to the rtRT-PCR in the majority (88.2\%) of patients with $C_{t} \leq 33$. Twelve of 14 (85.7\%) false-negative subjects with significant viral excretion $\left(C_{t} \leq 33\right)$ were asymptomatic, although conflicting evidence exists about the relationship between symptom severity and viral shedding [12]. False-positive test results were rarely observed, providing 99.6\%-specificity, exceeding the performance recommended by the World Health Organization (WHO) [13]. False-positive results have been reported in other antigen tests [14-16]. False positivity could be associated with high viscosity of tested specimen samples as well as interference with mucosal antibodies [17].

Finally, the BIOSYNEX COVID-19 Ag BSS Ag-RDT meets the current WHO criteria which stipulate that Ag-RDTs for SARS-CoV-2 antigens detection must have a sensitivity greater than $80 \%$ and a specificity greater than $97 \%$ (97-100\%) [13]. Furthermore, analytical performances comparable to those in our study AgRDT were previously reported for some Ag-RDTs in lateral flow immunoassay format $[7,9,14,18-28]$, while several studies have reported much lower sensitivity levels contrasting with consistently high specificity [3, 29-34]. In addition, the BIOSYNEX COVID-19 Ag BSS Ag-RDT also fulfilled the current recommendations of the French High Authority of Health (Haute Autorité de santé, Saint-Denis, France) for a screening Ag-RTD stating that, at minimum, AgRDTs would need to correctly identify significant proportions of symptomatic patients (sensitivity $\geq 80 \%$ ) as well as asymptomatic individuals (sensitivity $\geq$ $50 \%)$ and have very high specificity $(\geq 90 \%)[35]$.

We analyzed our results based on the estimated viral load in SARS-CoV-2 in the samples. There is an ongoing debate about the $\mathrm{C}_{\mathrm{t}}$ value corresponding to the threshold of infectivity (i.e., patient considered as contagious) $[7,36,37]$. La Scola et al. found that patients with $C_{t}$ values $>33$ are not infectious because of the low number of positive cultures [38]. The Centers for Disease Control and Prevention (CDC), Atlanta, USA, propose a $C_{t}$ cut-off value of 33 as a marker for contagiousness [39], and stress that $C_{t}$ values $\leq 20$ correspond to very high viral excretion [7, 36, 40, 41]. Our results demonstrate that the analytical performances of the BIOSYNEX COVID-19 Ag BSS Ag-RDT were much better in the event of a high viral load, i.e., in the case of significant viral excretion. These observations demonstrate the interest in the BIOSYNEX COVID-19 Ag BSS Ag-RDT as a rapid rule-in test for COVID-19 with samples at high viral load in symptomatic patients, for example, and raise caution about its use as a singular rule-out test, especially in samples with lower viral loads.

Our study has several strengths. All samples were collected from one nasopharynx with flocked swabs, optimal for evaluating Ag-RDT clinical performances in our study. The Ag-RDT and reference rtRT-PCR were carried out in parallel. The study population included various situations outside the hospital setting, with most young adults without comorbidities, who mostly had typical and mild COVID-19 symptoms when being symptomatic. This finding describes most individuals infected with SARS-CoV-2 and represents an essential group for limiting transmission in the community.

The study presents some limitations. Participants may have inadvertently reported general, non-specific symptoms as COVID-19 compatible symptoms. This investigation evaluated the BIOSYNEX COVID-19 Ag BSS antigen test; the results presented here cannot be generalized to other agencies-authorized SARS-CoV2 antigen tests. The BIOSYNEX COVID-19 Ag BSS antigen test characteristics might differ depending on whether an individual had previously tested positive. Finally, the CDC clarified that $C_{t}$ values using the rtRT-PCR platform is not a quantitative measure of viral burden in clinical samples and cannot be used to assess when a person is no longer infectious [42]. Consequently, our stratification of samples according to $C_{t}$ values of the $N$ gene does not necessarily reflect the actual infectivity of the participants.

\section{Conclusion}

The BIOSYNEX COVID-19 Ag BSS Ag-RDT demonstrated very high specificity and sufficient sensitivity for detecting SARS-CoV-2. Given the simple procedures and shorter turnaround time for this test, it is a promising option as an alternative diagnostic modality, especially in symptomatic COVID-19 or proven contagiousness. The test may also be used to test asymptomatic individuals under conditions of potential exposure to SARS-CoV-2 and as part of a population-level mass screening.

\section{Abbreviations}

Ag-RDT

Antigen-detecting rapid diagnostic tests

$\mathrm{CDC}$

Centers for Disease Control and Prevention

COVID-19

Coronavirus disease 2019

NAAT

nucleic acid amplification test

rtRT-PCR

real-time reverse transcription-polymerase chain reaction

SARS-CoV-2

Severe acute respiratory syndrome coronavirus 2

WHO 
World Health Organization

\section{Declarations}

Ethics approval and consent to participate. This study was approved by the local scientific committee of the Parc de l'Innovation, Strasbourg, France.

Consent to publication. All authors approved the submission of the manuscript for publication. All participants consented to take part in this study.

Availability of data and materials. Study data is available and can be used for academic or research purposes.

Competing interest. The authors report no conflicts of interest. The authors alone are responsible for the content and the writing of the paper.

Funding. No grant was received from the test manufacturers.

Contributions. FF, RD, and LB conceived and designed the research. FF, NA, and RD conducted the experiments, and STW conducted the statistical analyses. $\mathrm{RD}, \mathrm{STW}$, and LB analyzed the results and drafted the manuscript.

Acknowledgments. The authors thank all nurses and staff at the Centre Cardiologique du Nord, Saint-Denis, and Laboratoire Paris XV, Paris, and the patients for their willingness to participate in the study. We are grateful to Biosynex, Strasbourg, France, for providing the tests for the study. Dr. Serge Tonen-Wolyec was the recipient of the ERASMUS program between the University of Kisangani, the Democratic Republic of the Congo, and the University of Liège, Belgium.

\section{References}

1. Smithgall MC, Dowlatshahi M, Spitalnik SL, Hod EA, Rai AJ. Types of Assays for SARS-CoV-2 Testing: A Review. Lab. Med. 2020, 51, e59-e65.

2. Rai P, Kumar BK, Deekshit VK, Karunasagar I, Karunasagar I. Detection technologies and recent developments in the diagnosis of COVID-19 infection. Appl Microbiol Biotechnol. 2021 Jan;105(2):441-455.

3. Dinnes J, Deeks JJ, Berhane S, Taylor M, Adriano A, Davenport C, Dittrich S, Emperador D, Takwoingi Y, Cunningham J, Beese S, Domen J, Dretzke J, Ferrante di Ruffano L, Harris IM, Price MJ, Taylor-Phillips S, Hooft L, Leeflang MM, Mclnnes MD, Spijker R, Van den Bruel A; Cochrane COVID-19 Diagnostic Test Accuracy Group. Rapid, point-of-care antigen and molecular-based tests for diagnosis of SARS-CoV-2 infection. Cochrane Database Syst Rev. 2021 Mar 24;3(3):CD013705. doi: 10.1002/14651858.CD013705.pub2.

4. Li D, Li J. Immunologic testing for SARS-CoV-2 infection from the antigen perspective. J Clin Microbiol. 2020 Dec 14:JCM.02160-20.

5. Sars-CoV-2 Diagnostics Pipeline. 2020. Available online: https://www.finddx.org/covid-19/pipeline/ (accessed on 03 May 2021).

6. Mattiuzzi C, Henry B, Lippi G. Making sense of rapid antigen testing in SARS-CoV-2 diagnostics. Diagnosis (Berl). 2021 Apr 20. doi: 10.1515/dx-20210034.

7. Favresse J, Gillot C, Oliveira M, Cadrobbi J, Elsen M, Eucher C, Laffineur K, Rosseels C, Van Eeckhoudt S, Nicolas JB, Morimont L, Dogné JM, Douxfils J. Head-to-Head Comparison of Rapid and Automated Antigen Detection Tests for the Diagnosis of SARS-CoV-2 Infection. J Clin Med. 2021 Jan 13;10(2):E265.

8. Fitzpatrick MC, Pandey A, Wells CR, Sah P, Galvani AP. Buyer beware: inflated claims of sensitivity for rapid COVID-19 tests. Lancet. 2021 Jan 2;397(10268):24-25.

9. Schildgen V, Demuth S, Lüsebrink J, Schildgen O. Limits and Opportunities of SARS-CoV-2 Antigen Rapid Tests: An Experienced-Based Perspective. Pathogens. 2021 Jan 5;10(1):E38.

10. Newcombe RG. Two-sided confidence intervals for the single proportion: comparison of 362 seven methods. Statistics in Medicine. 1998;17:857-872.

11. Journal Officiel de la République Française. Ordonnance $n^{\circ}$ 2010-49 du 13 janvier 2010 relative à la biologie médicale. Available at: https://www.legifrance.gouv.fr/jorf/id/JORFTEXT000021683301/ (last access 21 January 2021).

12. Magleby R, Westblade LF, Trzebucki A, Simon MS, Rajan M, Park J, Goyal P, Safford MM, Satlin MJ. Impact of SARS-CoV-2 viral load on risk of intubation and mortality among hospitalized patients with coronavirus disease 2019. Clin Infect Dis. 2020 Jun 30:ciaa851.

13. World Health Organization. Interim guidance. Antigen-detection in the diagnosis of SARS-CoV-2 infection using rapid immune-assays. 11 September 2020. Available at: file:///C:/Users/prbel/Downloads/WHO-2019-nCoV-Antigen_Detection-2020.1-eng\%20(1).pdf (lass access : 04 May 2021).

14. Chaimayo C, Kaewnaphan B, Tanlieng N, Athipanyasilp N, Sirijatuphat R, Chayakulkeeree M, Angkasekwinai N, Sutthent R, Puangpunngam N, Tharmviboonsri T, Pongraweewan O, Chuthapisith S, Sirivatanauksorn Y, Kantakamalakul W, Horthongkham N. Rapid SARS-CoV-2 antigen detection assay in comparison with real-time RT-PCR assay for laboratory diagnosis of COVID-19 in Thailand. Virol J. 2020 Nov 13;17(1):177.

15. Tanimoto T, Matsumura M, Tada S, Fujita S, Ueno S, Hamai K, Omoto T, Maeda H, Nishisaka T, Ishikawa N. Need for a high-specificity test for confirming weakly positive result in an immunochromatographic SARS-CoV-2-specific antigen test: A case report. J Microbiol Immunol Infect. 2020 Dec 1;S16841182(20)30272-3.

16. Corman VM, Haage VC, Bleicker T, Schmidt ML, Mühlemann B, Zuchowski M, Jo WK, Tscheak P, Möncke-Buchner E, Müller MA, Krumbholz A, Drexler JF, Drosten C. Comparison of seven commercial SARS-CoV-2 rapid point-of-care antigen tests: a single-centre laboratory evaluation study. Lancet Microbe. 2021 Apr 7. doi: 10.1016/S2666-5247(21)00056-2.

17. S. Food and Drug Administration. Potential for false positive results with antigen tests for rapid detection of SARS-CoV-2 - Letter to clinical laboratory staff and health care providers, https://www.fda.gov/medical-devices/letters-health-care-providers/potential-false-positive-results-antigen-tests-rapiddetection-sars-cov-2-letter-clinical-laboratory (lass access : 04 May 2021).

Page 5/10 
18. Cerutti F, Burdino E, Milia MG, Allice T, Gregori G, Bruzzone B, Ghisetti V. Urgent need of rapid tests for SARS CoV-2 antigen detection: Evaluation of the SDBiosensor antigen test for SARS-CoV-2. J Clin Virol. 2020 Nov;132:104654.

19. Diao B, Wen K, Zhang J, Chen J, Han C, Chen Y, Wang S, Deng G, Zhou H, Wu Y. Accuracy of a nucleocapsid protein antigen rapid test in the diagnosis of SARS-CoV-2 infection. Clin Microbiol Infect. 2020 Oct 5:S1198-743X(20)30611-X.

20. Linares M, Pérez-Tanoira R, Carrero A, Romanyk J, Pérez-García F, Gómez-Herruz P, Arroyo T, Cuadros J. Panbio antigen rapid test is reliable to diagnose SARS-CoV-2 infection in the first 7 days after the onset of symptoms. J Clin Virol. 2020 Dec;133:104659.

21. Toptan T, Eckermann L, Pfeiffer AE, Hoehl S, Ciesek S, Drosten C, Corman VM. Evaluation of a SARS-CoV-2 rapid antigen test: Potential to help reduce community spread? J Clin Virol. 2020 Dec 5;135:104713.

22. Weitzel T, Legarraga P, Iruretagoyena M, Pizarro G, Vollrath V, Araos R, Munita JM, Porte L. Comparative evaluation of four rapid SARS-CoV-2 antigen detection tests using universal transport medium. Travel Med Infect Dis. 2020 Dec 2;39:101942.

23. Berger A, Nsoga MTN, Perez-Rodriguez FJ, Aad YA, Sattonnet-Roche P, Gayet-Ageron A, Jaksic C, Torriani G, Boehm E, Kronig I, Sacks JA, de Vos M, Bausch FJ, Chappuis F, Renzoni A, Kaiser L, Schibler M, Eckerle I. Diagnostic accuracy of two commercial SARS-CoV-2 antigen-detecting rapid tests at the point of care in community-based testing centers. PLoS One. 2021 Mar 31;16(3):e0248921.

24. Courtellemont L, Guinard J, Guillaume C, Giaché S, Rzepecki V, Seve A, Gubavu C, Baud K, Le Helloco C, Cassuto GN, Pialoux G, Hocqueloux L, Prazuck T. High performance of a novel antigen detection test on nasopharyngeal specimens for diagnosing SARS-CoV-2 infection. J Med Virol. 2021 May;93(5):3152-3157.

25. Mboumba Bouassa RS, Veyer D, Péré H, Bélec L. Analytical performances of the point-of-care SIENNA ${ }^{\text {TM }}$ COVID-19 Antigen Rapid Test for the detection of SARS-CoV-2 nucleocapsid protein in nasopharyngeal swabs: A prospective evaluation during the COVID-19 second wave in France. Int J Infect Dis. 2021 Mar 18;106:8-12.

26. Landaas ET, Storm ML, Tollånes MC, Barlinn R, Kran AB, Bragstad K, Christensen A, Andreassen T. Diagnostic performance of a SARS-CoV-2 rapid antigen test in a large, Norwegian cohort. J Clin Virol. 2021 Apr;137:104789.

27. Matsuda EM, de Campos IB, de Oliveira IP, Colpas DR, Carmo AMDS, Brígido LFM. Field evaluation of COVID-19 antigen tests versus RNA based detection: Potential lower sensitivity compensated by immediate results, technical simplicity, and low cost. J Med Virol. 2021 Mar 31. doi: 10.1002/jmv.26985.

28. Takeuchi Y, Akashi Y, Kato D, Kuwahara M, Muramatsu S, Ueda A, Notake S, Nakamura K, Ishikawa H, Suzuki H. The evaluation of a newly developed antigen test (QuickNavi-COVID19 Ag) for SARS-CoV-2: A prospective observational study in Japan. J Infect Chemother. 2021 Jun;27(6):890-894.

29. Albert E, Torres I, Bueno F, Huntley D, Molla E, Fernández-Fuentes MÁ, Martínez M, Poujois S, Forqué L, Valdivia A, Solano de la Asunción C, Ferrer J, Colomina J, Navarro D. Field evaluation of a rapid antigen test (Panbio COVID-19 Ag Rapid Test Device) for COVID-19 diagnosis in primary healthcare centres. Clin Microbiol Infect. 2020 Nov 13:S1198-743X(20)30697-2.

30. Scohy A, Anantharajah A, Bodéus M, Kabamba-Mukadi B, Verroken A, Rodriguez-Villalobos H. Low performance of rapid antigen detection test as frontline testing for COVID-19 diagnosis. J Clin Virol. 2020 Aug;129:104455.

31. Yamayoshi S, Sakai-Tagawa Y, Koga M, Akasaka O, Nakachi I, Koh H, Maeda K, Adachi E, Saito M, Nagai H, Ikeuchi K, Ogura T, Baba R, Fujita K, Fukui T, Ito F, Hattori SI, Yamamoto K, Nakamoto T, Furusawa Y, Yasuhara A, Ujie M, Yamada S, Ito M, Mitsuya H, Omagari N, Yotsuyanagi H, Iwatsuki-Horimoto K, Imai M, Kawaoka Y. Comparison of Rapid Antigen Tests for COVID-19. Viruses. 2020 Dec 10;12(12):1420.

32. Osterman A, Baldauf HM, Eletreby M, Wettengel JM, Afridi SQ, Fuchs T, Holzmann E, Maier A, Döring J, Grzimek-Koschewa N, Muenchhoff M, Protzer U, Kaderali L, Keppler OT. Evaluation of two rapid antigen tests to detect SARS-CoV-2 in a hospital setting. Med Microbiol Immunol. 2021 Jan 16. doi: 10.1007/s00430-020-00698-8.

33. Torres I, Poujois S, Albert E, Colomina J, Navarro D. Evaluation of a rapid antigen test (Panbio COVID-19 Ag rapid test device) for SARS-CoV-2 detection in asymptomatic close contacts of COVID-19 patients. Clin Microbiol Infect. 2021 Jan 6:S1198-743X(20)30782-5.

34. Torres I, Poujois S, Albert E, Álvarez G, Colomina J, Navarro D. Point-of-care evaluation of a rapid antigen test (CLINITEST ${ }^{\llbracket}$ Rapid COVID-19 Antigen Test) for diagnosis of SARS-CoV-2 infection in symptomatic and asymptomatic individuals. J Infect. 2021 May;82(5):e11-e12.

35. Haute Autorité de santé, Saint-Denis, France, 8 octobre 2020. Revue rapide sur les tests de détection antigénique du virus SARS-CoV-2. Available at : file:///C:/Users/prbel/Downloads/synthese_tests_antigeniques_vd\%20(1).pdf I

36. Jefferson T, Spencer EA, Brassey J, Heneghan C. Viral cultures for COVID-19 infectious potential assessment - a systematic review. Clin Infect Dis. 2020 Dec 3:ciaa1764.

37. Zou L, Ruan F, Huang M, Liang L, Huang H, Hong Z, Yu J, Kang M, Song Y, Xia J, Guo Q, Song T, He J, Yen HL, Peiris M, Wu J. SARS-CoV-2 Viral Load in Upper Respiratory Specimens of Infected Patients. N Engl J Med. 2020 Mar 19;382(12):1177-1179.

38. La Scola B, Le Bideau M, Andreani J, Hoang VT, Grimaldier C, Colson P, Gautret P, Raoult D. Viral RNA load as determined by cell culture as a management tool for discharge of SARS-CoV-2 patients from infectious disease wards. Eur J Clin Microbiol Infect Dis. 2020 Jun;39(6):1059-1061.

39. Centers for Disease Control and Prevention. Common Investigation Protocol for Investigating Suspected SARS-CoV-2 Reinfection. Available at : https://www.cdc.gov/coronavirus/2019-ncov/php/reinfection.html\#print (last access 03 May 2021)

40. Société Française de Microbiologie (SFM). Avis du 25 septembre 2020 de la SFM relatif à l'interprétation de la valeur de $C_{t}$ (estimation de la charge virale) obtenue en cas de RT-PCR SARS-CoV-2 positive sur les prélèvements cliniques réalisés à des fins diagnostiques ou de dépistage. Version 1 _ 25/09/2020. Available at : https://www.sfm-microbiologie.org/wp-content/uploads/2020/09/Avis-SFM-valeur-Ct-excre\%CC\%81tion-virale-_-Version-Finale25092020.pdf (last access 03 May 2021).

41. Yu F, Yan L, Wang N, Yang S, Wang L, Tang Y, Gao G, Wang S, Ma C, Xie R, Wang F, Tan C, Zhu L, Guo Y, Zhang F. Quantitative Detection and Viral Load Analysis of SARS-CoV-2 in Infected Patients. Clin Infect Dis. 2020 Jul 28;71(15):793-798.

Page 6/10 
42. Centers for Disease Control and Prevention. Clinical Questions about COVID-19: Questions and Answers. Updated Mar. 4, 2021. Testing, Isolation, and Quarantine for Persons Who Have Recovered from Previous SARS-CoV-2 Infection section. Available at : https://www.cdc.gov/coronavirus/2019ncov/hcp/faq.html (last access 01 July 2021).

43. Cohen J. A coefficient of agreement for nominal scales. Educ. Psychol. Meas. 1960;20:37-46.

44. Landlis JR, Koch GG. The measurement of observer agreement for categorical data. Biometrics. 1977;33(1):159-74.

45. Youden WJ. Index for rating diagnostic tests. Cancer. 1950;3(1):32-35.

\section{Tables}

Table 1. Characteristics of persons providing paired upper respiratory swab $(\mathrm{n}=967)$ for real-time reverse transcriptionpolymerase chain reaction (rRT-PCR) testing and BIOSYNEX COVID-19 Ag BSS rapid diagnostic testing for SARSCoV-2 at two private laboratory sites, by test results, Paris, France, spring 2021.

\begin{tabular}{|c|c|c|c|c|c|}
\hline \multirow[b]{2}{*}{ Characteristics } & \multirow[b]{2}{*}{$\begin{array}{l}\text { To number } \\
\text { of persons } \\
\text { (column \%) }\end{array}$} & \multicolumn{4}{|c|}{ Number of persons (row\%) } \\
\hline & & $\begin{array}{l}\text { rRT-PCR- } \\
\text { negative }\end{array}$ & $\begin{array}{l}\text { rRT-PCR- } \\
\text { positive }\end{array}$ & $\begin{array}{l}\text { Antigen- } \\
\text { negative }\end{array}$ & $\begin{array}{l}\text { Antigen- } \\
\text { positive }\end{array}$ \\
\hline Total & $967(100)$ & $819(84.7)$ & $148(15.3)$ & $844(87.3)$ & $123(12.7)$ \\
\hline \multicolumn{6}{|l|}{ Testing site } \\
\hline A & $741(74.6)$ & $633(85.4)$ & $108(14.6)$ & $651(87.9)$ & $90(12.1)$ \\
\hline B & $226(25.4)$ & $186(82.4)$ & $40(17.6)$ & $193(85.4)$ & $33(14.6)$ \\
\hline \multicolumn{6}{|l|}{ Sex } \\
\hline Female & $498(51.5)$ & $429(86.2)$ & $69(13.8)$ & $438(88.0)$ & $60(12.0)$ \\
\hline Male & $469(48.5)$ & $390(83.2)$ & $79(16.8)$ & $406(86.6)$ & $63(13.4)$ \\
\hline \multicolumn{6}{|l|}{ Age group, years } \\
\hline $18-49$ & $740(76.4)$ & $629(85.0)$ & $111(15.0)$ & $647(87.4)$ & $93(12.6)$ \\
\hline $50-64$ & $157(16.3)$ & $129(82.2)$ & $28(17.8)$ & $133(84.7)$ & $24(15.3)$ \\
\hline$\geq 65$ & $70(7.3)$ & $61(87.1)$ & $9(12.9)$ & $64(91.4)$ & $6(8.6)$ \\
\hline Median age (range) & $34(18-83)$ & $34(18-83)$ & $32(18-82)$ & $34(18-83)$ & $37(18-82)$ \\
\hline \multicolumn{6}{|l|}{ Any symptoms } \\
\hline$\geq 1$ & $245(25.3)$ & $165(67.4)$ & $80(32.6)$ & $168(68.6)$ & $77(31.4)$ \\
\hline None & $722(74.7)$ & $654(90.6)$ & $68(9.4)$ & $676(93.6)$ & $46(6.4)$ \\
\hline \multicolumn{6}{|l|}{ Days from the onset } \\
\hline $0-3$ & $107(43.3)$ & $38(35.5)$ & $69(64.5)$ & $41(38.3)$ & $66(61.7)$ \\
\hline 4-7 & $122(49.8)$ & $48(39.4)$ & $74(60.6)$ & $69(56.6)$ & $53(43.4)$ \\
\hline$>7$ & $16(6.9)$ & $11(68.7)$ & $5(31.3)$ & $12(75.0)$ & $4(25.0)$ \\
\hline$\leq 7$ & $229(93.1)$ & $86(37.6)$ & $143(62.4)$ & $110(48.0)$ & $119(52.0)$ \\
\hline Median (range) & $4(0-20)$ & $4(0-20)$ & $3(0-15)$ & $4(0-20)$ & $3(0-10)$ \\
\hline \multicolumn{6}{|l|}{ Travel } \\
\hline Yes & $344(35.6)$ & $330(95.9)$ & $14(4.1)$ & $337(98.0)$ & $7(2.0)$ \\
\hline No & $623(64.4)$ & $489(78.5)$ & $134(21.5)$ & $507(81.4)$ & $116(18.6)$ \\
\hline \multicolumn{6}{|c|}{ Contact Case (exposure to a diagnosed COVID-19 case) } \\
\hline Yes & $340(35.1)$ & $282(82.9)$ & $58(17.1)$ & $293(86.2)$ & $47(13.8)$ \\
\hline No/unknown & $627(64.9)$ & $537(85.7)$ & $90(14.3)$ & $551(87.9)$ & $76(12.1)$ \\
\hline \multicolumn{6}{|c|}{ Suspected COVID-19 } \\
\hline Yes $(\geqq 1$ COVID-19 symptom & 5) $212(21.9)$ & $149(70.3)$ & $63(29.7)$ & $151(71.2)$ & $61(28.8)$ \\
\hline No & $755(78.1)$ & $670(88.8)$ & $85(11.2)$ & $693(91.8)$ & $62(8.2)$ \\
\hline \multicolumn{6}{|l|}{ Preoperative assessment } \\
\hline Yes & $42(4.4)$ & $38(90.5)$ & $4(9.5)$ & $40(95.2)$ & $2(2.8)$ \\
\hline No & $925(95.6)$ & $781(84.4)$ & $144(15.6)$ & $804(86.9)$ & $121(13.1)$ \\
\hline \multicolumn{6}{|c|}{ Control of SARS-CoV-2 positive test results in past 30 days } \\
\hline Yes & $29(3.0)$ & $20(68.9)$ & $9(31.1)$ & $21(72.4)$ & $8(27.6)$ \\
\hline No/unknown & $938(97.0)$ & $799(85.2)$ & $139(14.8)$ & $823(87.7)$ & $115(12.3)$ \\
\hline
\end{tabular}


Table 2. Test results and performances characteristics of the BIOSYNEX COVID-19 Ag $B S S$ rapid diagnostic test compared with real-time reverse transcription-polymerase chain reaction (rRT-PCR) for SARS-CoV-2 testing among asymptomatic and symptomatic persons at two private laboratory sites, by test results, Paris, France, spring 2021.

\begin{tabular}{|c|c|c|c|}
\hline \multirow[b]{2}{*}{ Results and performances } & \multicolumn{3}{|c|}{ rRT-PCR (number of test, \%) } \\
\hline & Negative & Positive & Total \\
\hline \multicolumn{4}{|c|}{$\begin{array}{c}\text { BIOSYNEX COVID-19 Ag BSS results } \\
\text { All participants (n=967) }\end{array}$} \\
\hline Positive & $3(0.3)$ & $121(12.5)$ & $124(12.8)$ \\
\hline Negative & $816(84.4)$ & $27(2.8)$ & $843(87.2)$ \\
\hline Total & $819(78.8)$ & $148(21.2)$ & $967(100)$ \\
\hline \multicolumn{4}{|l|}{ Asymptomatic $(\mathrm{n}=722)$} \\
\hline Positive & $2(0.3)$ & $45(4.2)$ & $47(6.5)$ \\
\hline Negative & $652(90.3)$ & $23(5.2)$ & $675(95.5)$ \\
\hline Total & $654(90.6)$ & $68(9.4)$ & $722(100)$ \\
\hline \multicolumn{4}{|c|}{ Symptomatic $(\geq 1$ symptom) $(\mathrm{n}=245)$} \\
\hline Positive & $1(0.4)$ & $76(31.0)$ & $77(31.4)$ \\
\hline Negative & $164(67.0)$ & $4(1.6)$ & $168(68.6)$ \\
\hline Total & $165(67.4)$ & $80(32.6)$ & $245(100)$ \\
\hline \multicolumn{4}{|c|}{ Symptomatic ( $\leq 7$ days from symptom onset) $(\mathrm{n}=229)$} \\
\hline Positive & $1(0.5)$ & $72(31.4)$ & $73(31.9)$ \\
\hline Negative & $153(66.8)$ & $3(1.3)$ & $156(68.1)$ \\
\hline Total & $154(67.3)$ & $75(32.7)$ & $229(100)$ \\
\hline
\end{tabular}

BIOSYNEX COVID-19 Ag BSS performances (\%, 95\%CI)

All participants

Sensitivity $\quad 81.8(79.2-84.1)$

Specificity $\quad 99.6(98.9-99.8)$

$96.6(95.3-97.6)$

Asymptomatic

Sensitivity $\quad 79.4(76.3-82.2)$

Specificity $\quad 99.7(98.9-99.9)$

$97.3(95.8-98.2)$

$\begin{array}{cc}\text { NPV } & 97.2(95.7-98.2) \\ \text { Svmptomac } & \end{array}$

Sensitivity $95.0(91.5-97.1)$

Specificity $\quad 99.4(97.4-99.9)$

$95.6(92.2-97.5)$

NPV $99.3(97.2-99.8)$

Symptomatic ( $\leq 7$ days from onset)
Sensitivity

$99.4(97.3-99.9)$

PPV $\quad 95.7(92.2-97.7)$

NPV $99.4(97.3-99.9)$

${ }^{2}$ PPV and NPV were calculated according to the Bayes's formulae, by taking into account the official reported

prevalence of SARS-CoV-2-RNA positivity in COVID-19-suspected patients in Paris's area, France, of $12.2 \%$ on 12

April 2021 [Santé publique France 2021; https://www.santepubliquefrance.fr]

CI: Confidence interval; NVP: Negative predictive value; PPV: Positive predictive value

Table 3. Analytical performances of the BIOSYNEX COVID-19 Ag BSS rapid diagnostic test for the qualitative detection of the N protein of SARS-CoV-2 using 967 prospectively collected nasopharyngeal swab samples by reference rRT-PCR ${ }^{\#}$, according to their $N$ gene $C_{t}$ values. 
BIOSYNEX COVID-19 Ag BSS

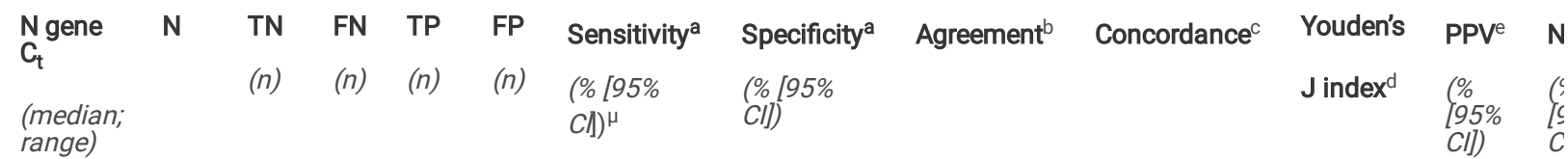

range)

\begin{tabular}{|c|c|c|c|c|c|c|c|c|c|c|c|c|}
\hline$\leq 20$ & $\begin{array}{l}17.9 \\
(13.9- \\
20.0)\end{array}$ & 35 & NA & 0 & 35 & NA & $\begin{array}{l}100(99.6 \\
-100)\end{array}$ & $\begin{array}{l}99.6(98.9 \\
-99.8)\end{array}$ & $\begin{array}{l}99.6(98.9 \\
-99.8)\end{array}$ & $\begin{array}{l}0.95(0.93- \\
0.96)\end{array}$ & $\begin{array}{l}99.6 \\
(98.9- \\
99.8))\end{array}$ & $\begin{array}{l}97.2 \\
(95.9 \\
-98.1)\end{array}$ \\
\hline
\end{tabular}

\begin{tabular}{|c|c|c|c|c|c|c|c|c|c|c|c|c|c|c|}
\hline $\mathrm{N}$ gene $C_{t}^{f}$ & & & & & & & & & & & & & & \\
\hline $\begin{array}{l}\text { by } \\
\text { rRT-PCR }\end{array}$ & $21-33$ & $\begin{array}{l}27.2 \\
(20.1- \\
33.0)\end{array}$ & 84 & NA & 14 & 70 & NA & $\begin{array}{l}83.3(80.7 \\
-85.6)\end{array}$ & $\begin{array}{l}99.6(98.9 \\
-99.8)\end{array}$ & $\begin{array}{l}98.1(97.0 \\
-98.8)\end{array}$ & $\begin{array}{l}0.65(0.62- \\
0.68)\end{array}$ & $\begin{array}{l}82.9 \\
(80.3- \\
85.2)\end{array}$ & $\begin{array}{l}96.7 \\
(95.3 \\
- \\
97.7)\end{array}$ & $\begin{array}{l}9 \\
(\underline{c} \\
- \\
9\end{array}$ \\
\hline
\end{tabular}

\begin{tabular}{|c|c|c|c|c|c|c|c|c|c|c|c|c|}
\hline $\begin{array}{l}>33 \\
-41\end{array}$ & $\begin{array}{l}35.9 \\
(34.0- \\
39.2)\end{array}$ & 29 & NA & 13 & 16 & NA & $\begin{array}{l}55.2(51.8 \\
-58.5)\end{array}$ & $\begin{array}{l}99.6(98.9 \\
-99.8)\end{array}$ & $\begin{array}{l}98.1(96.9 \\
-98.8)\end{array}$ & $\begin{array}{l}0.65(0.62- \\
0.68)\end{array}$ & $\begin{array}{l}54.8 \\
(51.4- \\
58.1)\end{array}$ & $\begin{array}{l}95.0 \\
(93.3 \\
-96.3)\end{array}$ \\
\hline
\end{tabular}

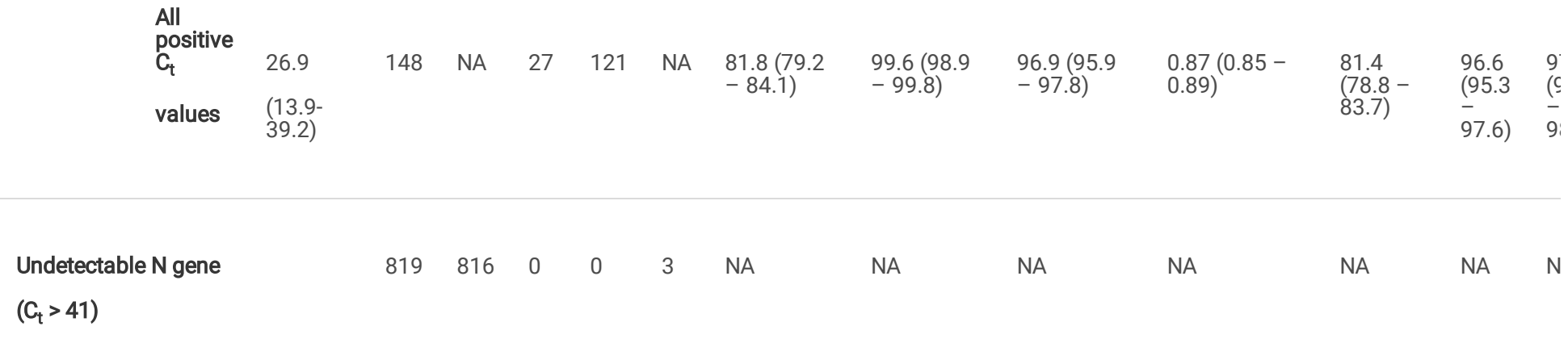

§Paired nasopharyngeal samples in each nostril were collected with a flocked swab for each volunteer patients by trained healthcare personnel (nurses, doctors or biologists). The collection of the two simultaneous samples was always carried out by the same operator. Molecular testing as well COVID-19 antigen detection were carried out on fresh samples;

a The results of SARS-CoV-2 RNA detection using the multiplex rtRT-PCR were used as the reference standard to estimate the sensitivity and specificity of the study Ag-RDT, with corresponding 95\% Cl;

${ }^{\mathrm{b}}$ Agreement $=\mathrm{TP}+\mathrm{TN} / \mathrm{TP}+\mathrm{FP}+\mathrm{TN}+\mathrm{FN}$, expressed in percentage;

c The Cohen's k coefficient calculation was used to estimate the concordance [43] and interpreted according the Landis and Koch scale [44], as follows: < 0 as indicating no agreement, $0-0.20$ as slight, $0.21-0.40$ as fair, $0.41-0.60$ as moderate, $0.61-0.80$ as substantial, and $0.81-1$ as almost perfect concordance;

d The accuracy of the test BIOSYNEX COVID-19 Ag BSS to correctly diagnose SARS-CoV-2 infection was estimated by Youden's $\mathrm{J}$ index $(\mathrm{J}=$ sensitivity + specificity - 1) [45];

e PPV and NPV were calculated according to the Bayes's formulae, by taking into account the official reported prevalence of SARS-CoV-2-RNA positivity in COVID-19-suspected patients in Paris's area, France, of 12.2\% on 12 ${ }^{\text {th }}$ April 2021 [Santé publique France 2021; https://www.santepubliquefrance.fr/];

$\mu$ 95\% confidence intervals in brackets were calculated by using the Wilson score bounds;

${ }^{£}$ The $C_{t}$ values of $\mathrm{N}$ gene detection by the reference Liferiver rRT-PCR were used to classify nasopharyngeal samples according to their level of SARS-CoV-2 RNA excretion; $C_{t}$ of 20 and 33 were taken as thresholds of very high and high SARS-CoV-2 RNA excretion, respectively, as previously stated (CDC 2020; 
Jefferson 2020; SFM 2020; Yu 2020); Viral loads with $C_{t}>33$ are considered low and correspond to moderate or very low viral excretion [36, 39-41]. Conversely, samples with $C_{t} \leq 33$ have a significant SARS-CoV-2 viral load, as in individuals symptomatic for COVID-19 or contagious. $C_{t}$ values $\leq 20$ indicate very high viral shedding [39-41].

\# The CE IVD-marked Novel Coronavirus (2019-nCoV) Real Time Multiplex RT-PCR Kit (Detection for 3 Genes) (Liferiver \& Shanghai ZJ Bio-Tech Co., Ltd, Shanghai, China) constituted the reference multiplex rRT-PCR for SARS-CoV-2 RNA detection. This assay can detect three coronavirus target genes simultaneously, including the SARS-like (SARS-CoV-2, SARS-CoV, bat SARS-like coronavirus) conserved region of envelope protein gene (E), RNA-dependent RNA polymerase gene (ORF1ab of RdRP gene), and nucleocapsid protein gene (N), using reverse transcription. Nucleic acid extraction was performed from $300 \mu \mathrm{L}$ elution volume of a nasopharyngeal flocked swab sample, using an EX3600 extractor (Liferiver \& Shanghai ZJ Bio-Tech Co.), according to the manufacturer's instructions, and finally eluted in $50 \mu \mathrm{L}$ (final volume). SARS-CoV-2 was detected in $5 \mathrm{~mL}$ of extracted RNA. Real-time PCR was conducted using CFX96 $6^{\text {TM }}$ Real-Time PCR Detection System (Bio-Rad Laboratories, Hercules, CA, USA) according to the manufacturer's instructions. The experiment and analysis of the results were performed according to the manufacturer's protocol.

$C_{t}$ : Cycle threshold; FN: False negative; FP: False positive; NA: Not attributable; NPV: Negative predictive value; PPV: Positive predictive value; rRT-PCR: real-time reverse transcription-polymerase chain reaction; TP: True positive; TN: True negative 